\title{
User Experience of Office Chairs and Anthropometrics of Female Chinese and Hong Kong Chinese Office and Factory Workers
}

\author{
Miriam E.F.R. Reitenbach ${ }^{1}$, Anne J. Jochems ${ }^{1}$, Johan F.M. Molenbroek ${ }^{*},{ }^{1}$, Roger Ball ${ }^{2}$ and \\ Daan J. van Eijk ${ }^{1}$ \\ ${ }^{I}$ Department of Applied Ergonomics and Design, Faculty of Industrial Design Engineering, Delft University of Technol- \\ ogy, Landbergstraat 15, 2628 CE Delft, The Netherlands \\ ${ }^{2}$ School of Design, The Hong Kong Polytechnic University, Hong Kong
}

\begin{abstract}
In Hong Kong it was noticed that female office and factory workers use chairs that are oversized and can't support their sitting posture in a comfortable way.

In order to set up general recommendations to design a more appropriate office chair, a research of the user experience of office chairs was conducted by means of interviews, questionnaires and focus groups.

Additionally, an anthropometric study was carried out on the seated body dimensions of 145 female Hong Kong office workers and 80 female Chinese factory workers.

Especially for the Hong Kong population a positive secular growth of body height in comparison to former studies of the same population was found. Referring to body proportions it was noticed that the upper body (the sitting height and shoulder height) of the measured women was on average relatively longer, whereas the legs were significantly shorter than those of Western female.
\end{abstract}

Keywords: Anthropometrics, office chair, Hong Kong, China.

\section{INTRODUCTION}

The Ergonomic Lab of the School of Design at the Hong Kong Polytechnic University initiated this study, as it was noticed that in Asia, and in this specific case China, many female office workers have problems with their office chairs.

Generally office chairs are designed for Western male and are therefore oversized for female Chinese office workers (Fig. 12). Chinese males will probably also have problems with the size of the chairs, but this study only focuses on the female office workers, as their problems are better noticeable. An interesting aspect, that will be elaborated later on, was the use of accessories like cushions on their chairs.

Two different studies, one on user experience and one on anthropometric measures were carried out to get a broad understanding of the context. The target group were female Hong Kong office workers and female Chinese factory workers.

Several anthropometrical surveys were conducted between 1961 and 2003 throughout China and Hong Kong, but most may no longer be valid due to the demographic shift and possible alterations in the body dimensions of the population. No former studies could be found on user experience of office chairs in China.

*Address correspondence to this author at the Department of Applied Ergonomics and Design, Faculty of Industrial Design Engineering, Delft University of Technology, Landbergstraat 15, 2628 CE Delft, The Netherlands; Tel: +31 15 2783086; Fax: +31 15 2787179;

E-mail: j.f.m.molenbroek@tudelft.nl
Therefore one of the fields of interest is whether secular changes did occur in the Hong Kong and Southern Chinese population since the last collections of comparable anthropometric data.

In China, Donghua University established a Human Science Research and Development Centre in Shanghai that initiated between 1997 and 1999 a study of the upper body dimensions of 1100 Chinese women [1].

Within the scope of the research project 'Body Shape Study for the Comparison between Korea and China' [2] Zhang measured 2800 women from East, North and South China starting from 1999 until 2002 with the aid of traditional Martin measuring techniques. A silhouetter and the American TC non-contact body scanner were also used to measure 12 body parameters.

In 1999 the Beijing Institute of Clothing Technology founded a Human Engineering Research Centre that initiated a comparison between Chinese and Korean college women. In 2003 a size survey of Chinese women was held for a lingerie brand [2].

For the present research it is most interesting to compare the published data of Lee and Evans' study held in 1981 and published in Pheasant [3]. The total sample size were 1557 subjects, about 36 body dimensions were measured of Hong Kong industrial workers. Also interesting are the outcomes of a research held in 1989 in South China [4] were about 19 body parameters of Southern Chinese women were measured. No information is known about the sample size of this study. 


\section{APPROACH}

This research was split up into two studies, one about user experience and an anthropometric study to gain insight into the problem field. As subjects, both female Hong Kong office workers and female Chinese factory workers were selected in order to cover a large field of diversity.

Therefore the first part of the study focused on the perception of comfort and usability of office chairs of female Hong Kong office workers and Chinese factory workers.

The aim of the second part of the study was to establish a more up-to-date database about the seated body dimensions of the above mentioned target group in order to set up guidelines for a more convenient office chair $[5,6]$. This part of the research is further described under subsection 5 .

\section{USER EXPERIENCE}

The study of the user experience of office chairs was held by means of interviews, focus groups and questionnaires in order to explore where the subsequent anthropometric research had to focus on. Special attention was given on the following topics:

- What were the physical problems with the chair?

- How did its users perceive the office chair?

- What kind of improvements should be made?

\subsection{Methods User Experience}

\subsubsection{Participants}

For the interviews nine subjects and for the focus groups another nine subjects were recruited at the Hong Kong Polytechnic University. Questionnaires were used to survey 144 office workers from the Hong Kong Polytechnic University and 80 factory workers from China. The subjects from Hong Kong were all employees of the Hong Kong Polytechnic University and were recruited via emails and personal contact.

The only criteria for selection were that the participants had to be female and working in an office environment. No further selection was made on pain level, age or educational level. The subjects from China were all female factory workers from the same factory. They were recruited by contacting the factory. Also here no further selection was made on pain level, age or educational level. The questionnaires were translated into Cantonese and were filled in with the aid of a translator, as some of the participants were illiterate. All of the subjects participated voluntary in the research as no compensations were given to the subjects.

\subsection{Procedures}

Three different data collection methods were used:

1. Interviews: Structured interviews took place in a separate room of the Hong Kong Polytechnic University in a personal atmosphere and lasted about half an hour. The interviews were recorded with a voice recorder. The subjects were interviewed about the physical and psychological aspects of their office chairs.

2. Focus groups: Three focus groups were carried out with respectively four, two and three subjects. The focus groups were recorded on video. One researcher served as a moderator while another researcher made annotations. The focus groups lasted between one and two hours and took place in a separate room at the Polytechnic University of Technology.

The focus groups started with a question form asking the subjects to rate the importance of the different aspects of the chairs and which aspects they liked most/less. Accordingly a group discussion was held. Finally the subjects were asked to design a personal chair in order to get insights about their favour in form and colour of office chairs.

3. Questionnaires: All subjects that were measured within the anthropometric research were interrogated with questionnaires that included questions about the most important problems users have with chairs, complaints and sitting hours.

The questionnaires were handed out before doing the measurements in a separate room of either the Hong Kong Polytechnic University or the factory in China.

All studies, the questionnaires, the interviews and focus groups took place during office hours.

\subsection{Data Analysis}

The outcome of the interviews was evaluated and compared based on the following aspects: size of the chair, adjustability, back and neck pain and psychological aspects.

The subsequent discussion was evaluated on the same aspects as with the interviews. With regard to the questionnaires the data was processed in tables and graphs.

\section{ANTHROPOMETRICS}

The second part of the research consisted of an anthropometric study of the seated body dimensions of 225 office and factory workers in Hong Kong and China.

The main issue of this research was to establish a database that is useful, reliable and accessible. Before starting the measurements, the exact method and the way of approach needed to be defined. The stepwise approach included the following topics:

- Identify the target group

- $\quad$ Set up a strategy to acquire the subjects

- Define the measurement variables and allowable errors

- Determine and test measuring method

\subsection{Methods Anthropometrics}

\subsubsection{Participants}

The following subsections discuss who the subjects are and how they were obtained and classified in order to allow a researcher to compare the sample with samples from related research projects.

\section{$\underline{\text { Sample Size }}$}

The study was conducted using a sample size of 225 subjects. Using a confidence level of $95 \%$ and taking into account that two different populations are measured (office 
workers in Hong Kong (145 subjects) factory workers in China (80 subjects)) a sample size of approximately 300-500 subjects would be recommended [7] to give more precise data of the population. However with regard to the small time span of the project a total sample size of 225 subjects was taken.

\section{Target Group}

The target group was primarily female Hong Kong Chinese office workers, who use office chairs and whose most common tasks are seated computer- and deskwork. There is a wide diversity of body dimensions due to nutritional improvements and genetic shift. Interesting to mention is that the Hong Kong women are a mix from all over China, many escaping the communist regime over the past 40 years. For that reason the diversity of the target population of the sample was extended to factory workers in the surrounding of Hong Kong in order to compare the datasets and find out the possible differences. Also the women here have migrated to South China for work, some even from rural areas far removed geographically. Due to this expansion it is also possible to compare the outcomes with the survey of Jürgens [4] held in South China.

The age range of the subjects was between 17 and 52 years. Older subjects sometimes did not want to tell their age, as this is a very sensitive issue in China. Age is a continuous variable and subjects in their 20's are anthropometrically different from individuals in their 50's. The average factory worker was remarkably younger than the average office worker. See Fig. (1) for age ranges of subjects.

\section{Recruitment of Subjects}

The female Hong Kong office workers were recruited at several departments of the Polytechnic University, as the study was initiated there. The Hong Kong office worker population was composed of lecturers, research staff and students who used an office chair intensively. The second group consisted exclusively of factory workers who were recruited at a factory in Huizhou, China, that produced audio devices. The factory workers did half of their work in sitting position, and one half in standing position. These factory workers used office chairs for their sitting work. All subjects participated voluntarily in the research. As compensation an information leaflet about the proper sitting position was handed out afterwards to the subjects.

\subsubsection{Variables}

Based on the outcomes of the user-experience research, several variables were defined to provide information of the body dimensions that are useful for designing a better office chair. Different one- and two-dimensional body measurements were taken into account, e.g. the shape of the spine.

The decision was taken to measure the subjects in their working clothes to guarantee a quick progress without intimidating the subjects. As a result several body dimensions, like the shape of the spine, could not be measured properly and were therefore left out from the survey. The subjects wore light and tight office or working clothing.

Next to the most relevant sitting dimensions, basic body size descriptions like stature, weight and age were measured and/or inquired to obtain general information of the subjects and allow a better categorisation. Similar research projects $[3,8]$ were compared and were used to select the following variables (see Fig. (2) for illustration):
1. Stature (without shoes)
2. Sitting height
3. Sitting to shoulder height
4. Lowest point scapula to sitting
5. Thigh thickness

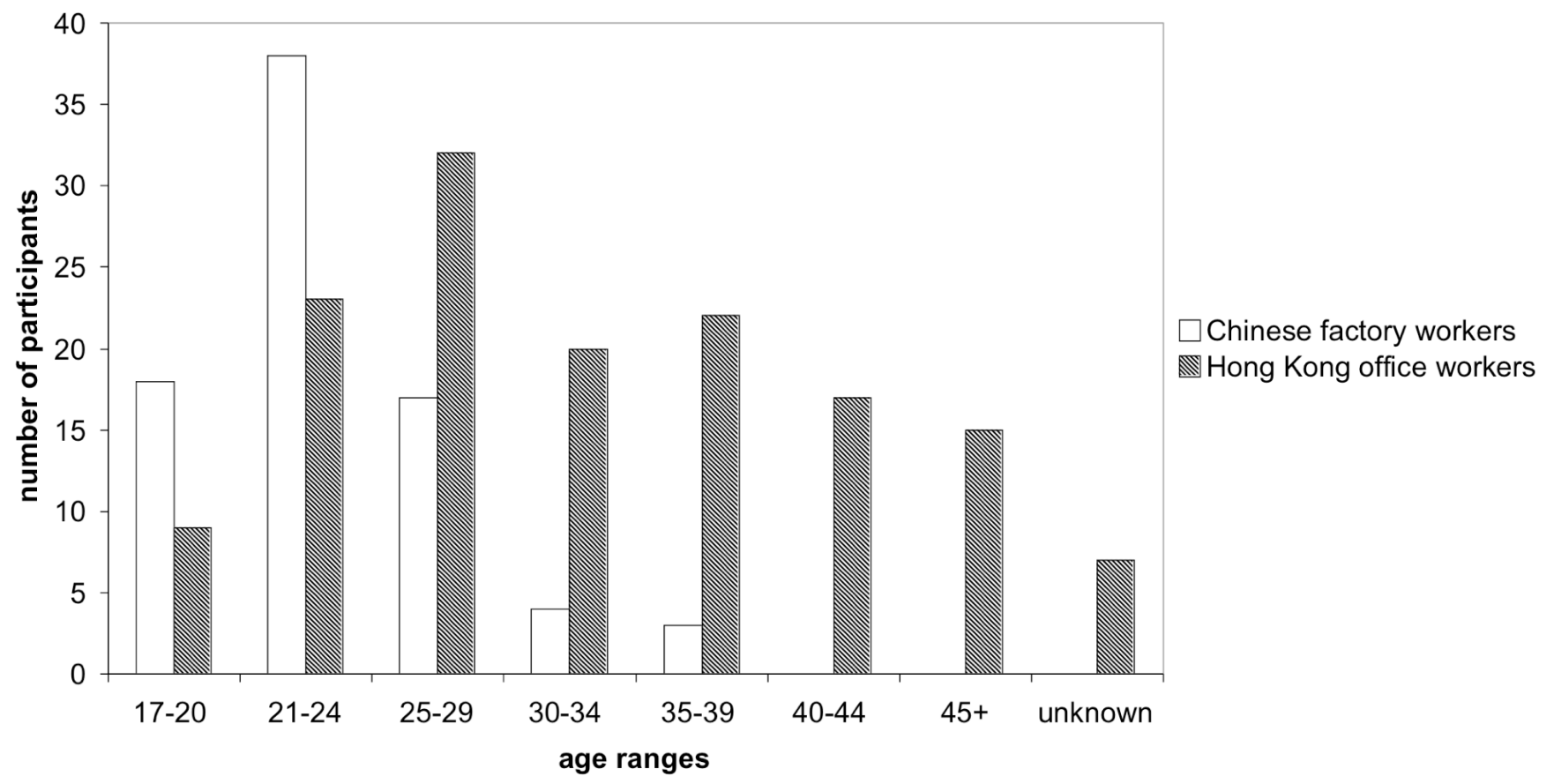

Fig. (1). Age ranges of the subjects 
6. Shoulder-elbow length

7. Shoulder breadth (bideltoid)

8. Hip breadth seated

9. Popliteal depth

10. Popliteal height

11. Heel height

12. Weight

13. Age
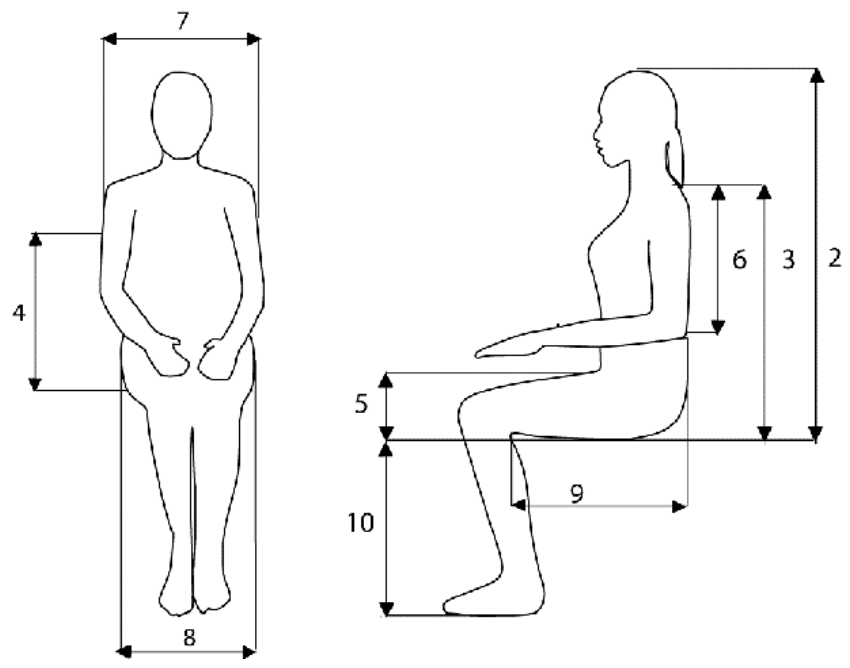

Fig. (2). Measurement variables.

\subsubsection{Measures}

Except for weight and age, the measurements were pointto-point distances and could be obtained manually.

Newer techniques like scanning or electromagnetic tracking were considered and tested. With regard to time, costs and space available, common manual measuring techniques turned out to be the most adequate for the purpose of this study.

Due these restrictions and the specific requirements for measuring the sitting position, the measuring instruments were custom-made for this particular study (Figs. 3, 4).

\subsubsection{Procedures}

Prior to the main research, a pilot study was conducted for quality control of the measuring technique, sequence and equipment with the same subjects that were interviewed.
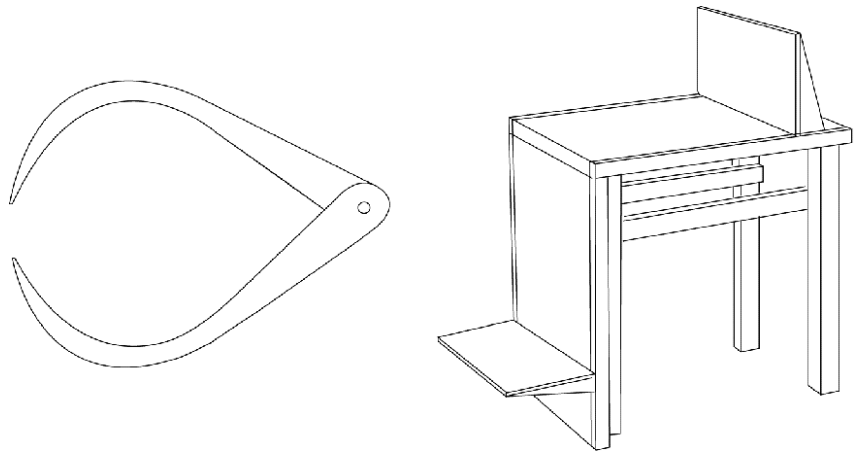

Fig. (3). Caliper and measuring chair used in the research.

Furthermore the measuring team was trained by repeating the measurements by means of intra- and inter-observer tests.

Each measurement started with a short description of the project and an explication how the subject will be measured. The time required for the measurements was 10-15 minutes per subject.

\subsubsection{Data Analysis and Dropouts}

The selected variables were measured based on international standard guidelines and former studies $[3,8,9]$. The collected data were processed using Excel and SPSS.

With regard to dropouts the extreme values were left out of the results, because they were not reliable (see 'number of measurements' in the measurements table). While carrying out the measurements, it was chosen to add the thigh thickness as a new measuring variable. For that reason the thigh thickness of the first 22 subjects measured in Hong Kong is not available.

\section{RESULTS}

\subsection{Results User Experience}

\subsubsection{Physical Aspects of the Used Office Chairs}

The most important aspect turned out to be the size of the chair. Fifteen of the 18 subjects from the interview and the focus group sessions stated that the size of the seated area is too deep and they can't reach the back of the chair. About half of the subjects that completed questionnaires in Hong Kong confirmed that the size of the chair was not appropriate for them.
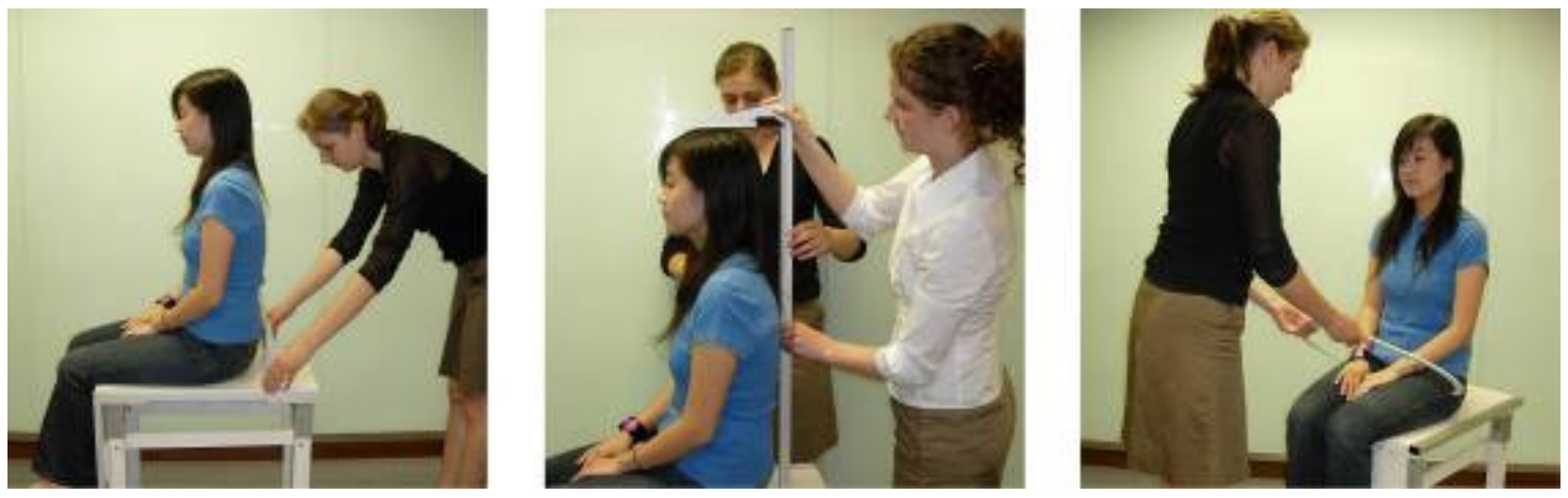

Fig. (4). Taking the measurements: popliteal depth, sitting height, hip breadth. 
About $10 \%$ of the 145 Hong Kong office workers stated in the questionnaires that they experience a lot of problems with their office chair, approximately $60 \%$ had some or a bit of complaints.

It turned out that $60 \%$ of the Chinese factory workers did not have any complaints about their office chair, only $37 \%$ had little complaints.

Furthermore the Hong Kong office workers regarded the size of the chair in relation to their small working space as a major issue as the armrests bumped again the desk.

The office chairs used in the factory had no armrests. The material of their office chairs was plastic. The factory workers put cardboard on their chairs in order to avoid sweating (see Fig. 5).

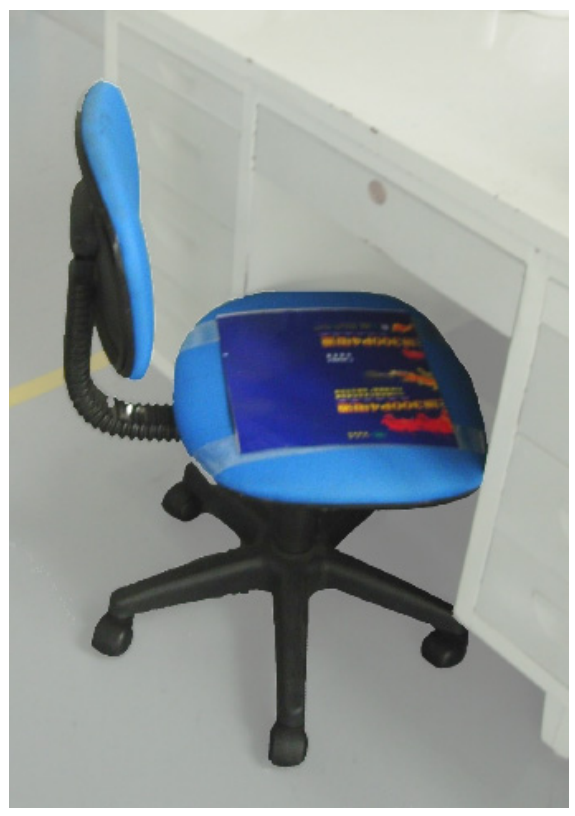

Fig. (5). Chair factory workers with cardboard.

Concerning the adjustability of the chairs 13 of the 18 subjects from the interviews and focus groups did not know how to adjust the chair and found it very difficult.

Several subjects could not even reach the handles while seated because of the size of the chair. These subjects would adjust the chair more frequently, if it would be easier.

Nine subjects of the focus group and interviews stated that they had back or neck pain that was either caused or aggravated by their chair. They mentioned that their back got tired because of the poor back support.

39 of the subjects from Hong Kong and 19 of the subjects asked in China through the questionnaire indicated that they suffered from back or neck pain when they used the chair for a longer period. Two of the subjects needed to go into physiotherapy, because of their sufferings. One subject also suffered from pain in her wrists, she used a wrist bench to ease her pain. In Fig. (6), it can be seen that material, back support and size of the back are the most important aspects. Design, colour, arm support are less important.

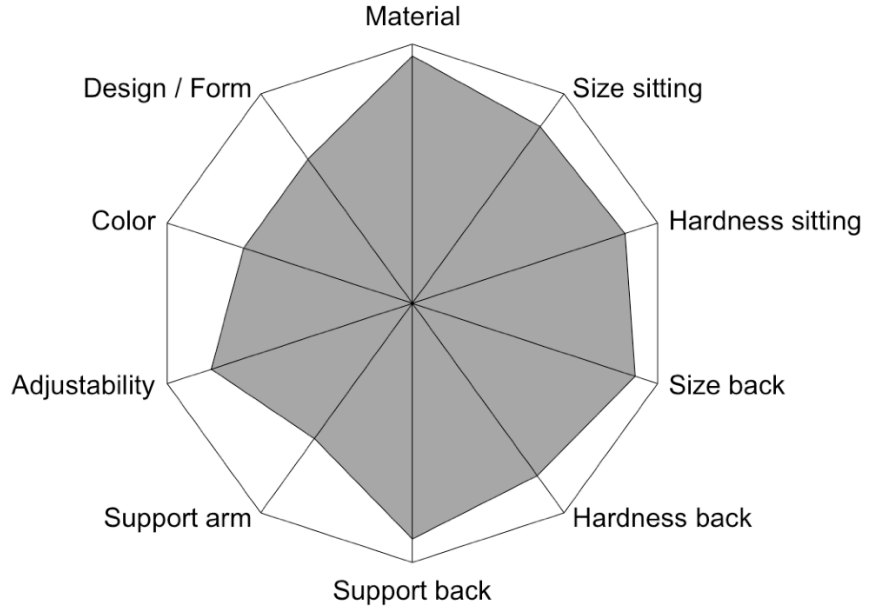

Fig. (6). Ranking importance different aspects office chair (focus groups).

A very interesting aspect was the use of a cushion, which was only noticed among the Hong Kong office workers. Eleven of the subjects that participated in the interviews and focus groups used a cushion. The cushion was used in order to support their back, as they couldn't reach the back, and/or in order to personalise it.

\subsubsection{Psychological Aspects of the Used Office Chairs}

It became evident that a good support and a good shape of the backrest are more important than the design and the colour of the chair.

Though, it turned out that for the office workers from Hong Kong the look of the chair was more important than for the factory workers.

Some of the subjects that were recruited in Hong Kong wanted to personalise their chair and have a chair that is outstanding and different to the other workers as nearly all chairs are the same in their office environment.

For all subjects from Hong Kong it was of particular importance that the chair looks clean and stains and dust are not visible.

The use and style of the cushion changed according to the professional position of the subject (see Fig. 7). The higher the position the fewer cushions were used or a cushion with a more medical appearance. Several subjects mentioned that they still would use a cushion, even if their chair supported them properly, in order to personalise their chair.

\subsubsection{Correlation Between Sitting Hours and Problems}

The factory workers all worked around 8 hours a day. Their working position changed between sitting and standing as they are alternating working tasks every couple of weeks. Consequently some just spent some hours sitting per day.

Some office workers from Hong Kong used their office chair more than 8 hours per day, or had an office chair at home which they use a lot as well. Some only stay seated few hours, as they needed to walk a lot around during their office hours. 

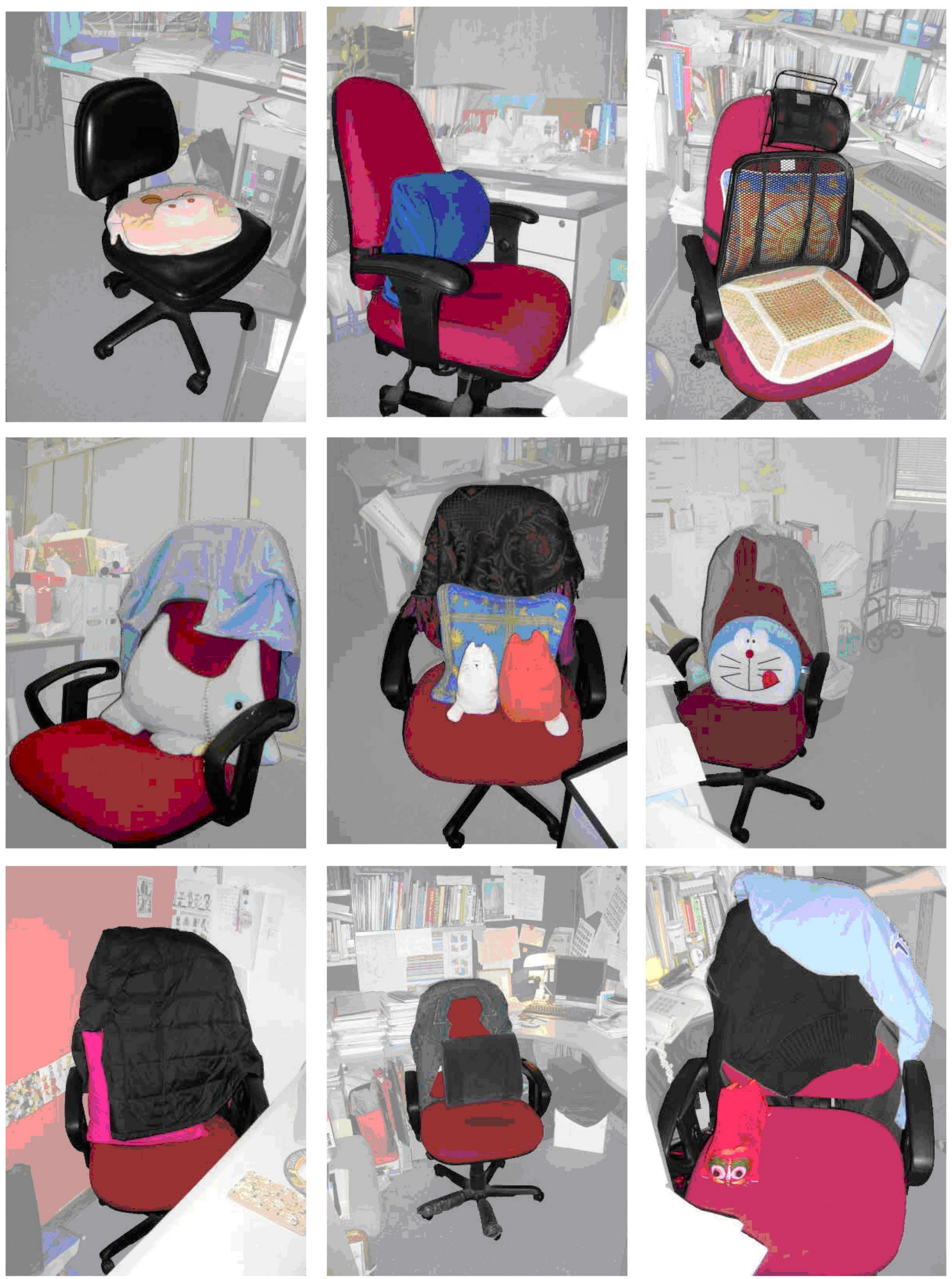

Fig. (7). Pictures of office chairs in Hong Kong. 
Table 1. Measuring Results of Hong Kong Office Workers and Chinese Factory Workers

\begin{tabular}{|c|c|c|c|c|c|c|c|c|c|c|}
\hline \multirow[b]{2}{*}{ Variable } & \multicolumn{5}{|c|}{ Hong Kong Office Workers } & \multicolumn{5}{|c|}{ Chinese Factory Workers } \\
\hline & $\mathbf{n}$ & $\bar{x}$ & sd & P3 & P97 & $\mathbf{n}$ & $\bar{x}$ & sd & P3 & P97 \\
\hline 1. Stature $[\mathrm{mm}]$ & 145 & 1579 & 55 & 1473 & 1683 & 80 & 1544 & 46 & 1452 & 1635 \\
\hline 2. Sitting height $[\mathrm{mm}]$ & 145 & 853 & 27 & 799 & 911 & 80 & 839 & 27 & 787 & 892 \\
\hline 3. Sitting shoulder height $[\mathrm{mm}]$ & 145 & 574 & 26 & 526 & 627 & 80 & 568 & 25 & 524 & 622 \\
\hline 4. Lowest point scapula [mm] & 143 & 445 & 24 & 399 & 494 & 80 & 435 & 23 & 393 & 483 \\
\hline 5. Thigh thickness [mm] & 122 & 125 & 11 & 107 & 147 & 78 & 126 & 10 & 109 & 147 \\
\hline 6. Shoulder-elbow length $[\mathrm{mm}]$ & 145 & 318 & 16 & 284 & 347 & 78 & 313 & 14 & 285 & 340 \\
\hline 7. Shoulder breadth (bideltoid) [mm] & 145 & 397 & 21 & 357 & 432 & 80 & 391 & 16 & 366 & 422 \\
\hline 8. Hip breadth seated $[\mathrm{mm}]$ & 144 & 368 & 24 & 331 & 423 & 80 & 354 & 20 & 322 & 392 \\
\hline 9. Popliteal depth $[\mathrm{mm}]$ & 145 & 443 & 25 & 397 & 497 & 80 & 440 & 20 & 398 & 477 \\
\hline 10. Popliteal height $[\mathrm{mm}]$ & 145 & 403 & 25 & 360 & 452 & 80 & 389 & 23 & 336 & 434 \\
\hline 11. Weight $[\mathrm{kg}]$ & 143 & 52 & 7 & 41 & 68 & 80 & 49 & 6 & 39 & 61 \\
\hline
\end{tabular}

$\mathrm{n}=$ Number of measurements; $\overline{\mathrm{X}}=$ Mean; sd $=$ Standard deviation; $\mathrm{P} 3=3^{\text {th }}$ Percentile; $\mathrm{P} 97=97^{\text {th }}$ percentile.

The correlation between the sitting hours per day and the problems is slightly positive. The more hours a female office worker uses her chair the more complaints she has about it. There is a similar correlation between age and the amount of problems.

Table 2. Measuring Results of Combined Population of Hong Kong Office Workers and Chinese Factory Workers

\begin{tabular}{|l|c|c|c|c|c|}
\hline \multirow{2}{*}{\multicolumn{1}{|c|}{ Variable }} & \multicolumn{5}{|c|}{$\begin{array}{c}\text { Hong Kong Office Workers \& } \\
\text { Chinese Factory Workers } \\
\text { Together }\end{array}$} \\
\cline { 2 - 6 } & n & $\overline{\mathbf{X}}$ & sd & P3 & P97 \\
\hline \hline 1. Stature [mm] & 225 & 1567 & 54 & 1462 & 1679 \\
\hline 2. Sitting height [mm] & 225 & 848 & 28 & 794 & 902 \\
\hline 3. Sitting shoulder height [mm] & 225 & 572 & 25 & 526 & 626 \\
\hline 4. Lowest point scapula [mm] & 223 & 442 & 24 & 397 & 487 \\
\hline 5. Thigh thickness [mm] & 200 & 126 & 11 & 107 & 147 \\
\hline 6. Shoulder-elbow length [mm] & 223 & 316 & 16 & 285 & 345 \\
\hline 7. Shoulder breadth (bideltoid) [mm] & 225 & 395 & 20 & 360 & 430 \\
\hline 8. Hip breadth seated [mm] & 224 & 363 & 24 & 324 & 418 \\
\hline 9. Popliteal depth [mm] & 225 & 442 & 24 & 398 & 494 \\
\hline 10. Popliteal height [mm] & 225 & 398 & 25 & 350 & 446 \\
\hline 11. Weight [kg] & 223 & 51 & 7 & 41 & 67 \\
\hline
\end{tabular}

$\mathrm{n}=$ Number of measurements; $\overline{\mathrm{X}}=$ Mean; sd $=$ Standard deviation; P3 $=3^{\text {th }}$ Percentile; $\mathrm{P} 97=97^{\text {th }}$ percentile.

\subsection{Results Anthropometrics}

The obtained data about the seated body dimensions of Hong Kong office workers and Chinese factory workers were first processed into a database and accordingly analysed and compared with other databases.

\subsubsection{General Measurement Results}

In Table 1, the measuring results of Hong Kong office workers and Chinese factory workers are shown. In Table 2, the measurement results of a combined population of both groups are shown.

While processing the data it was noticed that some of the data were skewed or had kurtosis. This is a common phenomenon for "fat measurements", as hip breadth, thigh thickness [8]. Because of the skewness or kurtosis the measurements are not normally distributed. As in that case the $\mathrm{P}_{3}$ and $\mathrm{P}_{97}$ cannot be calculated by the mean and the standard deviation anymore, the $\mathrm{P}_{3}$ and $\mathrm{P}_{97}$ of each measurement are given.

\section{ANALYSIS}

\subsection{Comparison of Hong Kong Office Workers with Chinese Factory Workers}

As can be seen in Table 3, most of the body dimensions of the Hong Kong office workers show significant higher values than those of the Chinese factory workers. In Fig. (8), it can be seen that the difference of stature is mostly according to sitting height and popliteal height and lesser extend to popliteal depth. Also a difference in weight can be noticed.

Measurements, like thigh thickness and popliteal depth of the Hong Kong office workers are about equal to those of the factory workers.

Fig. (9) indicates that the Hong Kong office workers show more variety in weight and length than the Chinese factory ladies. Chinese factory ladies fence are in the lower left part of the scatter plot. When neglecting the fact that the two sample sizes are not similar, it can be said that Chinese factory ladies are in general smaller and lighter than the Hong Kong office ladies.

\subsection{Secular Changes}

In Fig. (10), it can be seen that there is a significant decrease of thigh thickness. This might be explained by the different measuring method, but there can also be a trend that the women got thinner.

To get an insight whether secular changes have occurred in the body dimensions of Chinese women, the results of this study were compared with two research studies held about two decades ago $[3,4]$. The reported data were compared 
Table 3. Differences in Measurements of Hong Kong Office Workers and Chinese Factory Workers (Present Study)

\begin{tabular}{|c|c|c|c|c|c|}
\hline Variable & Mean Difference & SD Difference & $\mathbf{t}$ & Df & Significant \\
\hline 2. Sitting height $[\mathrm{mm}]$ & 14 & 1 & 4 & 223 & $*$ \\
\hline 3. Sitting shoulder height [mm] & 7 & 1 & 2 & 223 & \\
\hline 5. Thigh thickness [mm] & -1 & 1 & 0 & 198 & \\
\hline 6. Shoulder-elbow length [mm] & 5 & 3 & 2 & 221 & $*$ \\
\hline 7. Shoulder breadth (bideltoid) [mm] & 6 & 5 & 2 & 201 & $*$ \\
\hline 8. Hip breadth seated [mm] & 13 & 4 & 4 & 222 & $*$ \\
\hline
\end{tabular}

$\mathrm{SD}=$ Standard Deviation; $\mathrm{t}=$ Difference between sample means; $\mathrm{Df}=$ Degree of freedom.

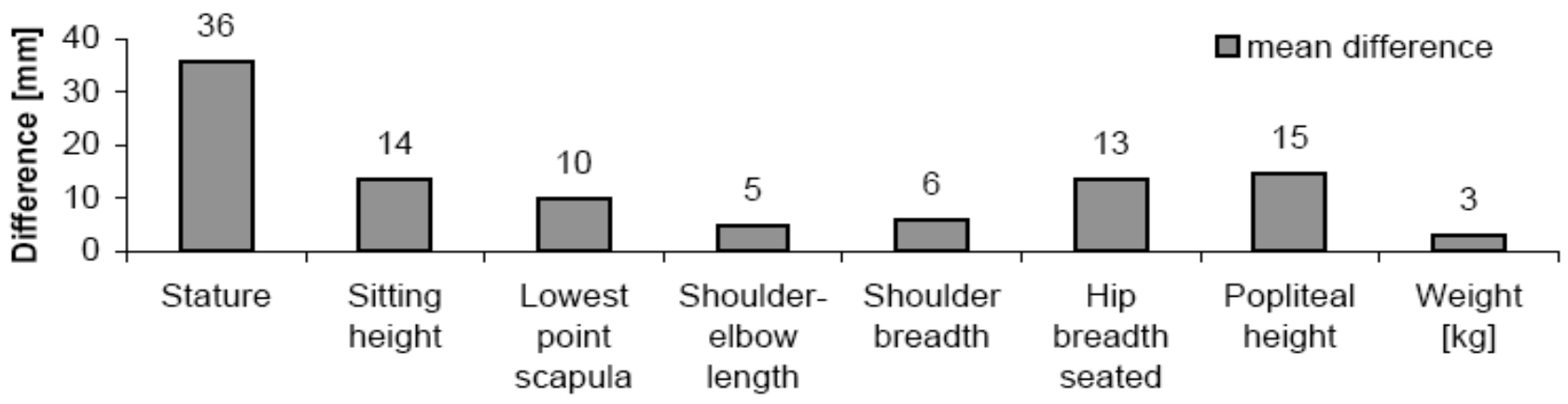

Variable

Fig. (8). Significant values when comparing mean Hong Kong office workers with mean Chinese Factory workers (present study).

with the data of merely Hong Kong office workers measured in the present research.

The comparison shows that a general increase in the body dimensions of female workers in Hong Kong has taken place over the last 25 years.

Additionally the data about the Hong Kong office workers combined with the Chinese factory workers were compared with the retrieved data of a survey held before 1989 on the body dimensions of the female South China population [4]. Table 4b and Fig. (11) show that the body dimensions of Southern Asian women have increased since the last collection of data. The difference in body height is significantly higher than the one of the data of Hong Kong office workers compared with the data of the survey held in 1981 by Lee and Evans. Striking is the higher sitting height in comparison to the stature. This can possibly explained by the measuring method of the values of the former researches. This might also be an explanation for the decrease in hip breadth.

\subsection{Comparison of Chinese Women with Western Women}

In order to make a comparison, scale factors set up by Pheasant [8] were used to find out if there are differences in body proportions in comparison to Western women. These scale factors calculate the sizes of body segments of a certain population when only the mean and the standard deviation of the body height are known. Here the mean and standard deviation of the stature of the population measured in this study were translated with the scale factors and consequently compared with the values of the female Western population as given by Pheasant [8].

It has to be noted that these scale factors are set up for Western women and populations that are compared should have the same body proportions. Consequently the outcomes are supposed to serve as indicator.

It was found that the upper body (the sitting height and shoulder height) of the Chinese women was relatively longer, whereas the lower part of the body was relatively shorter.

\subsection{Heel Height}

The Hong Kong office workers have an average heel height of $27 \mathrm{~mm}$.

It was noticed that all China factory workers wore the same shoes, but as some shoes where older and more worn out than other ones the heel height varied. 


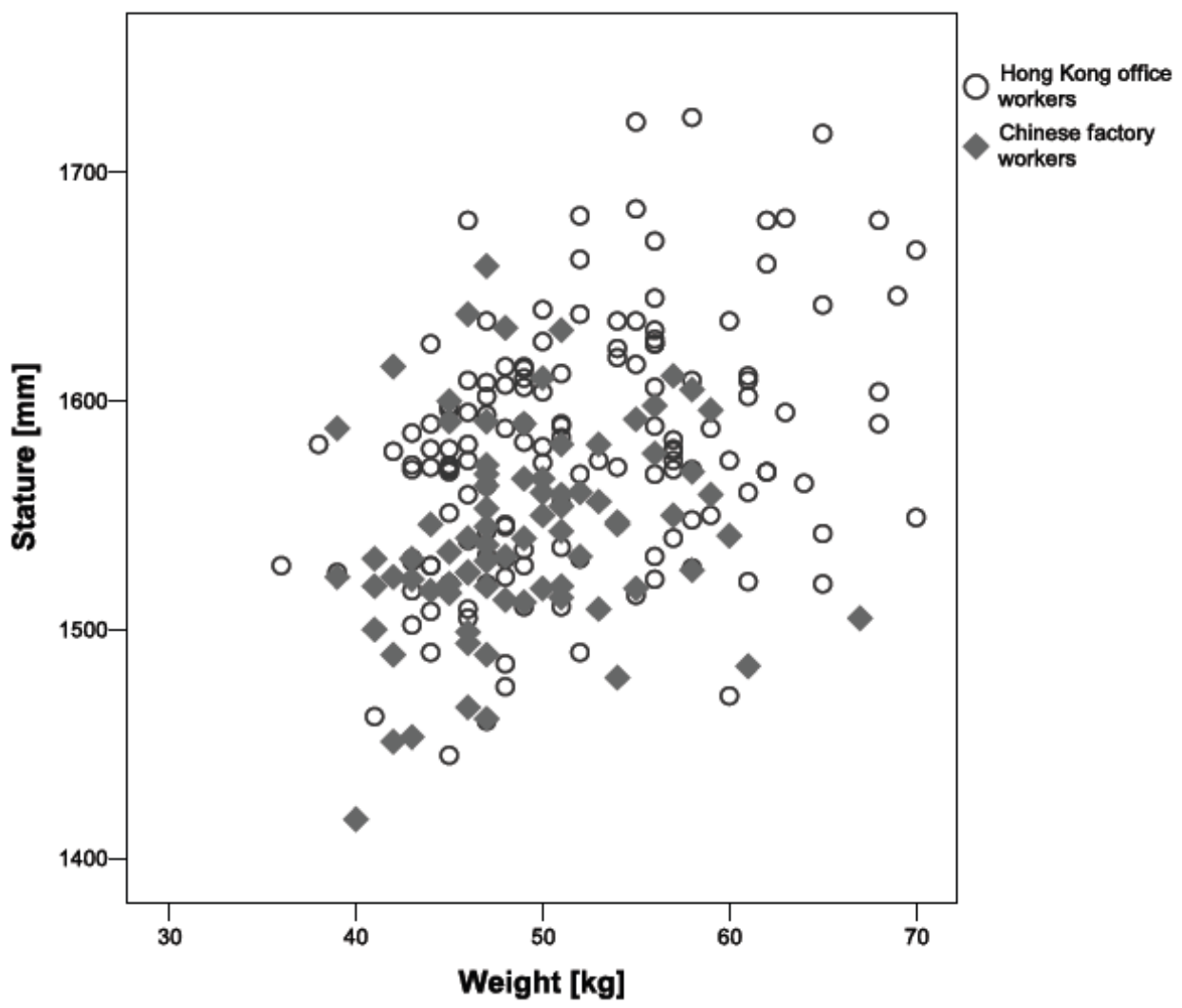

Fig. (9). Correlation between length and weight of Hong Kong office workers and Chinese factory workers.

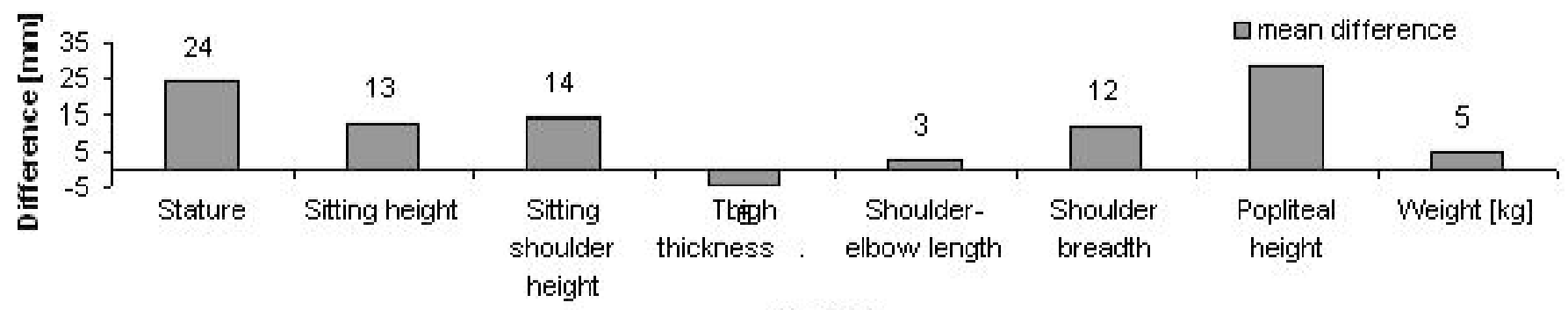

\section{Variable}

Fig. (10). Significant values comparing Hong Kong industrial workers [3] with Hong Kong office workers (present research).

Table 4a. Differences in Mean and Standard Deviation of Measurements Hong Kong Office Workers (Present Research) and Hong Kong Industrial Workers [3]

\begin{tabular}{|c|c|c|c|c|c|}
\hline \multirow{2}{*}{ Variable } & \multicolumn{5}{|c|}{ Measurements Hong Kong Office Workers (Present Study) - Hong Kong Industrial Workers 1981} \\
\hline & Mean Difference & SD Difference & $\mathbf{t}$ & Df & Significant \\
\hline 1. Stature $[\mathrm{mm}]$ & 24 & -5 & 5 & 144 & * \\
\hline 2. Sitting height $[\mathrm{mm}]$ & 13 & -10 & 6 & 144 & * \\
\hline 3. Sitting shoulder height $[\mathrm{mm}]$ & 14 & -3 & 7 & 144 & * \\
\hline 4. Lowest point scapula $[\mathrm{mm}]$ & N.A. & & & & \\
\hline 5. Thigh thickness $[\mathrm{mm}]$ & -5 & -3 & -5 & 121 & $*$ \\
\hline 6. Shoulder-elbow length $[\mathrm{mm}]$ & 3 & 0 & 2 & 144 & * \\
\hline 7. Shoulder breadth (bideltoid) [mm] & 12 & -8 & 7 & 144 & * \\
\hline 8. Hip breadth seated $[\mathrm{mm}]$ & N.A. & & & & \\
\hline 9. Popliteal depth [mm] & N.A. & & & & \\
\hline 10. Popliteal height $[\mathrm{mm}]$ & 28 & -4 & 14 & 144 & $*$ \\
\hline 11. Weight $[\mathrm{kg}]$ & 5 & 0 & 8 & 142 & * \\
\hline
\end{tabular}


The average heel height or their factory shoes is approximately $10 \mathrm{~mm}$.

\section{DISCUSSION}

Between 1961 and 2003 several anthropometric surveys were conducted. For this research the survey done by Lee and Evans in 1981 about Hong Kong industrial workers [3] and another survey held in South China [4] were compared in order to investigate whether secular changes occurred in the Hong Kong and Southern Chinese population.

Table 4 shows that the body dimensions of Hong Kong compared with the outcomes of the survey held by Lee and Evans in 1981 have increased over the last 24 years.

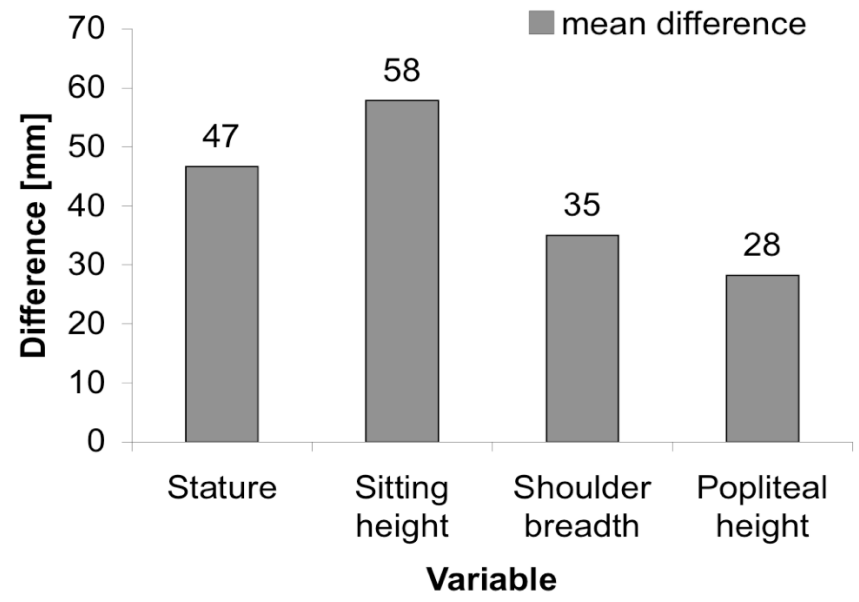

Fig. (11). Female population South China [4] compared with combined population of Hong Kong office workers and Chinese factory workers (present research).

The combined group of Hong Kong office workers and Chinese factory workers compared with the data of Jürgens in 1989 indicates an even higher positive secular growth.

However, these data must be interpreted carefully, as the sample size of the research held in 2005 was not representative for the whole Southern population of China. Still, it is noticeable that the body proportions of the combined group are larger than the ones of the Chinese women, measured in 1989.

The data of the Hong Kong office workers compared with the study held in 1981 the thigh thickness has decreased and the combined data compared with the survey held in 1989 the hip breath seated has become less. This might be due to the fact that fat measurements are more difficult to measure and different approaches were applied, or there might be a trend that Chinese women are becoming thinner.

The remarkable higher values of the popliteal height and the sitting height of the data of the combined group might be a consequence of the different measuring equipment used.

When comparing the anthropometrics of Hong Kong office workers and Chinese factory workers it is noticeable that most of the body dimensions of the Hong Kong office workers were longer than the ones of the factory workers.

The difference might be due to the age difference between the two groups. Here it has to be noted that the average age of the China factory workers (23,3 years) is lower than the office workers $(32,1$ years). This is due to the cultural phenomenon that Chinese female factory workers usually work until they get married. According to Roede and Wieringen [10] Dutch women are fully-grown at the age of 18-19. No information about Asian women could be found.

In the database of the factory group two 17-year old subjects were included, which are with respect to age at the border of the above-mentioned range.

If the data of these two subjects were excluded from the statistics, then the same results were obtained. Hence it can be stated that the age difference in the sample size has a negligible influence.

As both groups were measured in spring 2005, with the same measuring equipment and by the same measurers, deviations cannot be attributed to external factors.

Table 4b. Differences in Mean and Standard Deviation of Measurements Chinese Workers (Present Research) and Female Population South China [4]

\begin{tabular}{|c|c|c|c|c|c|}
\hline Variable & \multicolumn{5}{|c|}{ Measurements Hong Kong and Chinese Workers (Present Study) - South China <1989 } \\
\hline 2. Sitting height $[\mathrm{mm}]$ & 58 & -3 & 31 & 224 & $*$ \\
\hline 3. Sitting shoulder height $[\mathrm{mm}]$ & N.A. & & & & \\
\hline 5. Thigh thickness [mm] & N.A. & & & & \\
\hline 6. Shoulder-elbow length $[\mathrm{mm}]$ & N.A. & & & & \\
\hline 7. Shoulder breadth (bideltoid) [mm] & 35 & 1 & 27 & 224 & * \\
\hline 8. Hip breadth seated $[\mathrm{mm}]$ & -7 & -1 & -4 & 223 & N.A. \\
\hline
\end{tabular}

${ }^{1}$ As not all the same variables where measured in the studies held in 1981 and 1989, several body .dimensions could not be compared

$\mathrm{SD}=$ Standard Deviation; $\mathrm{t}=$ Difference between sample means; $\mathrm{Df}=$ Degree of freedom. 
It was found out that Hong Kong office workers show more variety in weight and body height than the Chinese factory workers (see Fig. 9). This might also be due to the larger age range of the Hong Kong office workers.

When comparing the body dimensions of Chinese women with Western women it was found that the upper body (the sitting height and shoulder height) of Asian women is relatively longer, whereas the lower part of the body is relatively shorter. Especially the popliteal depth of Asian women turned out to be noticeable shorter.

This confirms the outcomes of earlier studies held by Eveleth and Tanner in 1976 [3] who showed that far Eastern samples have proportionally shorter lower limbs than European male and female samples.

This comparison demonstrates that it can be presumed that office chairs designed for the Western population are not necessarily adequate for Asian women. Still this comparison is only an approximation and will be interesting for further investigation.

Due to the above-mentioned anthropometric differences between Western women and Hong Kong and Chinese women it is not surprising that the latter experience several problems with their office chair.

The user research showed that many subjects, especially the Hong Kong office workers, had back pain, which was in most cases explained by the poor back support and because they don't adjust their office chair very well.

The differences in outcome between the Hong Kong office workers and the Chinese factory workers were noticeable. The most remarkable fact was that hardly any of the Chinese factory workers encountered complaints. This may be due to the active working position and the movements they make while working. Further it is possible that the subjects didn't dare to answer honestly because the questionnaire was filled in by a staff member as some of them were illiterate.

Still, the support of the upper part of the body is an issue, as their working position is mostly leaning forward, which caused some of the subjects pain in their waist or back. The chairs used in Hong Kong were covered with textiles whereas the office chairs in the factory were made of plastic. The factory workers reported that the chairs get very hot, especially in the summer. For that reason most of the chairs in the factory were covered with cardboard in order to avoid sweating.

The factory workers did not mention the appearance of their chairs, whereas the Hong Kong office workers are concerned about the appearance of their chair. For the latter mentioned it is important that their chair looks clean and that they don't sweat, because of the material of the chair. Another interesting fact is the use of a cushion that was not only used to support the chair, but also to personalise their office chair.

\section{RECOMMENDATIONS FOR AN IMPROVED OF- FICE CHAIR}

- Smaller or adjustable seat width (based on results of this study $33-45 \mathrm{~cm}$ )
If you are small you don't want to sit in a chair that makes you wide.

- Less deep seat pan or adjustable backrest (based on results of this study $35-43 \mathrm{~cm}$ ).

If the users back can not reach the back rest, the Hong Kong users will fill this room with own material, which is not always supporting the back, and especially the pelvis, in a proper way.

- Reachable handles for small ladies.

Currently the handles are mostly not used because the users cannot manipulate the handles.

- It should be easier to adjust vertical seat, because currently their body weight is too low to get the seat down.

Halve of the body weights are lower then $51 \mathrm{~kg}$, which makes it difficult to push the seat downwards

- Additional colourful skins to personalize the chair, see Fig. (5).

It would be starting a new trend to create skins like a mobile phone offers to its customers to personalize your chair; the Hong Kong users are very eager to dress their chairs.

- The skins must have a high resistance against sweatspots; the users are eager to avoid seeing sweat spots.

The researchers observed a high priority to avoid any glance of a sweat or dirt spot.

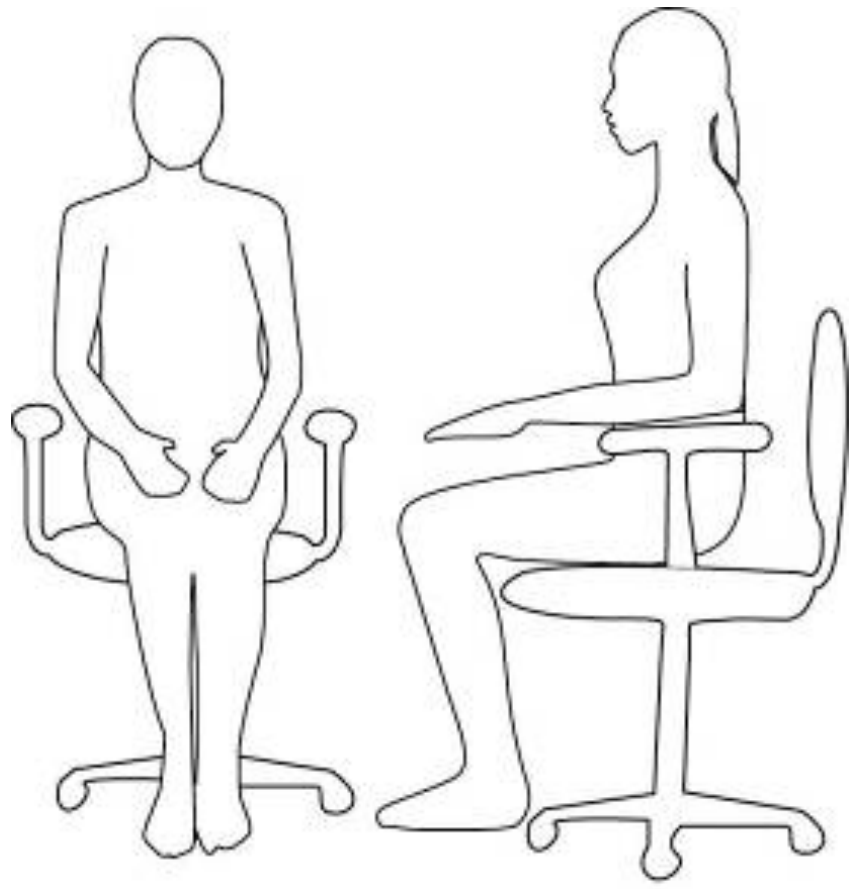

Fig. (12). Hong Kong Chinese women sitting on present office chair.

\subsection{Methodological Aspects}

This study was intended to give a first insight into the approach of anthropometric studies in China. It should be mainly used to get ideas about the emerging trends in the female population in China, such as secular changes in com- 
parison with former studies and differences in body dimensions between Chinese and Western women.

The results of this study also indicate in which parts of this study further investigation would be useful with more subjects.

For a more extensive study newer and proper measuring equipment is necessary to make more precise and quicker measurements.

One drawback of the used measuring equipment was that is was not suitable for the biggest hip breadths, a wider measuring box would be necessary.

It would also be useful to use the computer as an error reporter, which alerts the measurers when an improbable value is imported.

Some women did not want to report their age or weight. As these measurements are very important another way to get this data must be found.

Some tools, like for example the caliper were sometimes terrifying to some women. It is important to explain first or demonstrate how and why this instrument is used.

\section{ACKNOWLEDGEMENTS}

The authors would like to acknowledge the Polytechnic University Hong Kong, especially the School of Design, for participating in the project and offering kind assistance.
They also thank Gold Peak Electronics Hong Kong and Huizhou, China, for making it possible to carry out a part of the research in their factory and offering kind assistance during the research.

\section{REFERENCES}

[1] Abend J. Clothing for osteoporosis sufferers affords new niche. Bobbin: 1997.

[2] Fan J, Yu W, Hunter L. Clothing appearance and fit: Science and technology. The Textile Institute. Cambridge: Woodhead Publishing Limited and CRC Press LLC 2004; 181-2.

[3] Pheasant S. Bodyspace: Anthropometry, Ergonomics and the Design of Work. London: Taylor and Francis 1996; Vol. 2.

[4] Jürgens HW, Aune IW, Piepe U. Internationaler Anthropometischer Datenatlas. FB587. Bundesanstalt für Unfallforschung. Dortmund: Schriftenreihe der Bundesanstalt für Arbeitsschutz; 1989

[5] Environmental Health \& Safety Center [online]. Last updated unknown. [cited February 23, 2005]. Available from: http://www.nc su.edu/ehs/www99/right/handsMan/office/ergonomic.html.

[6] Staarink HAM. Sitting Posture, Comfort, and Pressure: Assessing the Quality of Wheelchair Cushions. Delft: Technische Universiteit Delft; 1995.

[7] The survey system [online]. 2004. [cited March, 2005]. Available from: http://www.surveysystem.com/sscalc.htm.

[8] Molenbroek JFM. Op maat gemaakt: Menselijke maten voor het ontwerpen en beoordelen van gebruiksgoederen. Series Physical Ergonomics 3. Delft: Delftse Universitaire Pers; 1994.

[9] Lohman TG, Roche AF, Martorell M. Anthropometric standardization reference manual. Champaign, Illinois: Human kinetic Books; 1988.

[10] Roede MJ, van Wieringen JC. Tijdschrijft voor Sociale Gezondheidszorg. Growth Diagrams 1980. Netherlands third nation-wide survey. Supplement 1985. Algemene Nederlandse Vereniging voor Sociale Gezondheidszorg 1985; Jaargang 63, 11. 